Audit sampling strategies and frauds: An Evidence from Africa

\begin{tabular}{|r|l|}
\hline Journal: & Managerial Auditing Journal \\
\hline Manuscript ID & MAJ-06-2020-2695.R2 \\
\hline Manuscript Type: & Research Paper \\
\hline Keywords: & $\begin{array}{l}\text { Logistic regression, Fraud triangle, Random and non-random sampling, } \\
\text { Audit sampling, Africa }\end{array}$ \\
\hline \multicolumn{2}{|l}{} \\
\hline
\end{tabular}

SCHOLARONE ${ }^{\text {Tw }}$

Manuscripts 


\title{
Audit sampling strategies and frauds: An evidence from Africa
}

\begin{abstract}
:
Purposes: This research investigates how professionals such as accountants, auditors, senior civil servants and academics perceive the use of audit sampling strategies adopted by professionals to increase detection rates of frauds and corruption within the public sector in Africa. It also examines the respondents' perceived values regarding the reasons for committing frauds, types of frauds and corruption as well as the aspects of audit sampling strategies to tackle frauds.
\end{abstract}

Design/methodology/approach: This research employs non-parametric statistics and logistic regression to analyse the respondents' opinions regarding the state of frauds and corruption in Africa (particularly in Tunisia and non-Tunisia countries), the common factors behind people committing frauds, including the types of frauds and corruption and the respondents' opinions on the use of audit sampling strategies (non-random and random) to examine the instances of frauds and corruption.

Findings: The findings indicate that most respondents prefer to use non-probabilistic audit sampling rather than more robust sampling strategies such as random sampling and systematic random sampling to detect frauds and corruption. In addition, although there are some minor statistical differences between the countries in terms of the respondents' perceived values on skimming fraud and on the use of audit random sampling to tackle rampant corruption in Africa, the overall findings indicate that opinions do not significantly differ between the respondents from Tunisia and other countries in terms of the types of fraud, the reasons for committing fraud and the auditing sampling strategies used to investigate the frauds.

Research Implications/limitations: This research serves as an analytical exploratory study to instigate further audit sampling research to combat rampant fraud and corruption in the public sector in Africa.

Originality/value: There are few or non-existent studies investigating the application of audit sampling strategies in Africa countries, particularly to examine the application of audit random sampling and audit non-random sampling strategies to detect fraudulent activities and corruption. Correspondingly, this research carries strategic implications for accountants and auditors to successfully detect fraudulent activities and corruption in Africa.

\section{Keywords:}

Logistic regression, Fraud triangle, Ch-square analysis, Logit model, Auditing Audit sampling, Random and non-random sampling, Africa 


\section{Introduction}

Using correlation analysis of gross domestic product per capita, literacy, income inequality and freedom of the media, Warf (2017) indicates that many of the world's most corrupt governments are located in Africa. This severity of corruption relates to most of the fundamental issues in African countries, such as poverty, patrimonial cultures, nepotism, poorly developed civil societies and the lack of freedom of speech. This failure of combating fraudulent and corrupt activities within the African public sector has been due to ineffective corporate governance (Boly et al., 2020; Gustavson, 2014), which distorts the allocation of resources, minimises the benefits of foreign aid and discourages foreign investment. In fact, according to the Corruption Perception Index (CPI), Africa is the lowest performing region, and imminent action is needed in this area (Transparency International, 2020). Accordingly, the secondary data were extracted from Transparency International (2020) of the country ranking based on the Corruption Perception Index to evaluate the levels of corruption and fraud in Africa between 2015 and 2020. Table 1 below illustrates the secondary data extracted from Transparency International (2020). A ranking of 1 indicates a clean government, while a higher ranking implies higher corruption levels in the country.

Table 1: Country Ranking Based on the Corruption Perception Index

\begin{tabular}{|l|r|r|r|r|r|r|}
\hline \multirow{2}{*}{ Country } & \multicolumn{7}{|c|}{ Year } \\
\cline { 2 - 7 } South Africa & $\mathbf{2 0 1 5}$ & $\mathbf{2 0 1 6}$ & $\mathbf{2 0 1 7}$ & $\mathbf{2 0 1 8}$ & $\mathbf{2 0 1 9}$ & $\mathbf{2 0 2 0}$ \\
\hline Central Africa & 61 & 64 & 71 & 73 & 70 & 69 \\
\hline Tunisia & 145 & 159 & 156 & 149 & 153 & 146 \\
\hline Nigeria & 136 & 75 & 74 & 73 & 74 & 69 \\
\hline
\end{tabular}

The data from Table 1 is portrayed graphically in Figure 1 and indicates that corruption levels in Africa have not yet declined substantially enough to warrant effective and clean corporate governance, as the corruption ranking trend remained relatively stable between 2015 and 2020. However, some slight ranking fluctuation is perceptible in the African countries, with Table 1 revealing that some countries, such as South Africa, Central Africa and Nigeria, have worsened in terms of corruption levels during recent years. For example, in 2015, South Africa ranked $61^{\text {st }}$ (cleaner government), but in 2020, the country rank worsened to $69^{\text {th }}$. Conversely, Tunisia's ranking improved slightly from $76^{\text {th }}$ in 2015 to $69^{\text {th }}$ in 2020 , implying corruption levels in the country have declined slightly. 


\section{Table 2 - Fraudulent Activities in Africa}

\begin{tabular}{|c|l|l|}
\hline $\mathbf{1}$ & $\begin{array}{l}\text { Expense } \\
\text { reimbursement } \\
\text { schemes (ERS) }\end{array}$ & $\begin{array}{l}\text { Falsification of information about expenses that causes the government to overcompensate staff in } \\
\text { the form of inflated expenses. For example, any governmental staff member who is in a position to } \\
\text { incur travel expenses is potentially capable of committing this fraud. }\end{array}$ \\
\hline $\mathbf{2}$ & $\begin{array}{l}\text { Asset } \\
\text { misappropriation }\end{array}$ & $\begin{array}{l}\text { The theft of government assets (such as cash or inventory) and the misuse of government assets } \\
\text { (such as using a government car for a personal trip). }\end{array}$ \\
\hline $\mathbf{3}$ & Skimming & $\begin{array}{l}\text { The process by which cash is removed from the government office before it enters the accounting } \\
\text { system (for example, the receipt of the cash is never reported to the institution, unrecorded } \\
\text { governmental revenues and understated government revenues). }\end{array}$ \\
\hline $\mathbf{4}$ & Corruption & $\begin{array}{l}\text { The wrongful use of influence in a governmental dealing to procure a personal benefit. Corruption } \\
\text { occurs in various forms, including bribery, undisclosed payments, illegal gratuities and collusion. }\end{array}$ \\
\hline $\mathbf{5}$ & Shell companies & $\begin{array}{l}\text { Traders, vendors and suppliers who exist fictitiously only on paper. The purpose is to bill the } \\
\text { government for services not rendered or products not delivered. The scheme involves an insider in } \\
\text { the management and takes a variety of forms. }\end{array}$ \\
\hline
\end{tabular}

expected to raise the risks of corruption. Accordingly, this is one justification of this study stimulating further discussion towards cleaner government, increasing societal welfare, and reducing misappropriation of emergency funds.

Moreover, bribery continues to hinder the access to public services where the Global Corruption Barometer for Africa has revealed that approximately 130 million people in the 35 countries revealed they had paid a bribe to access essential public services such as health care (Transparency.org, 2019 Transparency International, 2020). Moreover, there are a variety of fraudulent activities and corruption (as indicated in Table 2) from expenses reimbursement schemes, asset misappropriation, skimming, corruption, shell companies, money laundering, espionage, and illegal insider trading and such sophisticated techniques make it difficult for auditors to detect fraudulent (Armah-Attoh, Gyimah-Boadi and Chikwanha, 2007; Heath, 2000; Pillay, 2014).

\section{Country Ranking based on Corruption Perception Index} 180

160

140

100

60

40

Figure 1: The Ranking Based on the Corruption Perception Index in Africa 


\begin{tabular}{|c|l|l|}
\hline $\mathbf{6}$ & $\begin{array}{l}\text { Money } \\
\text { laundering }\end{array}$ & $\begin{array}{l}\text { Disguising the origins of money obtained through illegal sources as if it was obtained from legal } \\
\text { sources or transforming the proceeds of crime into legitimate assets. Otherwise, the fraudsters } \\
\text { would be unable use the money as it would connect them to the illegal activity. }\end{array}$ \\
\hline $\mathbf{7}$ & Espionage & $\begin{array}{l}\text { Obtaining information that is not normally publicly available in return for monetary compensation. } \\
\text { Espionage can be channelled by using a traditional way or more advanced IT hacking systems. It may } \\
\text { also involve seeking to influence decision-makers for the benefit of an outside or foreign power. } \\
\text { Espionage can be either governmental or industrial espionage. }\end{array}$ \\
\hline $\mathbf{8}$ & $\begin{array}{l}\text { Illegal insider } \\
\text { trading }\end{array}$ & $\begin{array}{l}\text { Buying or selling a security while in possession of non-public information about the security. It may } \\
\text { also include tipping such information. Examples of illegal insider trading are friends, business } \\
\text { associates and family members trading the securities after receiving confidential information and } \\
\text { government employees, who learned of such information and take advantage of the confidential } \\
\text { information. }\end{array}$ \\
\hline
\end{tabular}

Since fraud and corruption leads to negative impacts and corrodes the public's trust it could undermine the sector's effectiveness (Nyamori, Abdul-Rahaman and Grant, 2017; Pillay, 2014; Soobaroyen Tsamenyi, and Sapra, 2017; Yeboah-Assiamah, 2016). Hence, it is expected that the use of more robust sampling strategies will increase detection rates and reduce fraud in the public sector. This in turn will lead to stimulating economic growth in Africa since most African countries are characterised by a relatively high level of rampant fraudulent activities and corruption among officials within the public sector (Armah-Attoh, Gyimah-Boadi and Chikwanha, 2007; Nyamori, Abdul-Rahaman and Grant, 2017; Yeboah-Assiamah, 2016).

Correspondingly, the major aim of this study is to provide direction on audit sampling strategies to successfully combat fraud and corruption in Africa drawing on data collected from three African countries i.e. Tunisia, South Africa and Nigeria. The three countries are selected because they follow the Association of Chartered Certified Accountants (ACCA) and Chartered Financial Analyst (CFA) (Ngoc Huy, 2014). This study serves as a preliminary exploration in the application of audit sampling strategies to combat corruption in Africa's public sector.

The rest of the study is organized as follows. The next section shows the gap in the literature by presenting the literature on Auditing, Frauds and Corruption in Africa and literature on Audit-Sampling Strategies, followed by the methodology used. Section four reports the main empirical results, and section five of the article draws conclusions and provides elements for consideration in the public sector of Africa.

\section{Literature Review}

Public service organisations need to be more transparent and accountable in their operations while improving the policies and procedures to improve the accountability and access to public information. As such, improvements of audit quality procedures in Africa's public sector could be a solution to overcome these issues and improvements in accountability of public sector. In order to maintain 
better audit quality procedures, audit sampling techniques play a major role (Marazzi, 2016; Marazzi and Tille, 2017). However, the guidance for practitioners on how to use audit sampling methods has not appeared robustly in the auditing literature along with no validation of the guidance. In addition, evidence shows that the majority of auditors use non-statistical sampling techniques (Chen and Leitch, 1999; Peek, Neter and Warren, 1991). Thus, the current research is considered paramount because a correct application of audit sampling strategies would lower non-detection risks in auditing. This research is considered vital for reducing fraudulent activities particularly within the public sector in Africa.

Recent trends in auditing practices for multinational and larger corporations indicate the developmental use of big data and social media in audit sampling (Appelbaum, Kogan and Vasarhelyi (2017); Vasarhelyi, Kogan and Tuttle (2015), although in smaller companies and small to medium enterprises, auditors have to perform more traditional tasks of inspecting structured data such as 10,000 conventional receipts a year, in which auditors need to perform audit sampling. Otherwise, it would not be possible to audit all receipts (census), which may take more than a year to audit individual receipts facing limited time and resource. This study applies to smaller firms and small to medium enterprises. However, as technology trends have developed, data for auditing can include exponentially growing online unstructured and machine-generated data. This has gradually transformed the work of auditors to audit unstructured and massive data particularly for multinationals and larger corporation in developed countries such as the UK, US, Germany, Japan and others. Accordingly, more auditors may employ big data and draw comparisons over larger populations. In addition, the methodology of automation and artificial intelligence (AI) are required by auditors to inspect a massive amount of big data. Nevertheless, this study focuses on audit sampling for structured or conventional data in emerging and developing economies in Africa.

Although there have been abundant studies examining the application of audit sampling strategies within the auditing literature in general (Peek, Neter and Warren, 1991; Chen and Leitch, 1999; Beldona and Francis, 2007; Marazzi, 2016; Marazzi and Tille, 2017), there are very few studies investigating the application of audit sampling strategies in Africa, particularly to examine the application of audit random sampling and audit non-random sampling strategies to detect fraudulent activities and corruption. In addition, there has been little academic research on audit sampling and its strategic guidelines at institutional levels (Elder et al., 2013). 
This paper draws on studies developed in two areas of literature (Figure 2): studies pertaining to frauds, corruption, and auditing in Africa, and studies relating to general audit sampling techniques.

Figure 2 - Relevant empirical literature

Figure 3 - Input-Process-Output Framework

The input-process-output (IPO) framework (Figure 3) can be used to illustrate the relevant literature pertaining to auditing, fraud, and corruption in Africa. The IPO framework is an extensively used approach in systems analysis for describing the structure and sequence of auditing (Johnstone, Gramling, and Rittenberg, 2015).
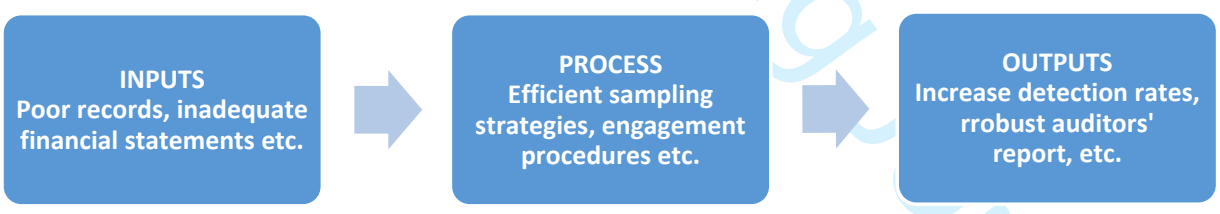

Figure 3 illustrates the inputs of auditors are listed among other financial records, accounting transactions, complete ledger, and others. While the process of auditing (Figure 3 ) is robust sampling strategies to increase detection rates of frauds and corruption, audit engagement, substantive procedures and others. The process also includes regular training for auditors and continuous professional development (CPD) of auditors to lower non-detection risks. Lastly, the outputs of auditing comprise robust auditing reports to successfully detect fraud and corruption, which will subsequently lead to the country's stability. 
Ngoepe and Ngulube (2016) indicated that poor record keeping was the main factor leading to the failure of auditing within the public sector in Africa and therefore, to a poor 'input' to be examined by the auditors as indicated in Figure 3. Hence, from an 'input' perspective, non-detection risks in auditing are still considered relatively high in Africa because of poor record keeping in the African public sector. Poor record keeping includes inadequate records of transactions, no itemisation of accounting transactions, etc. This phenomenon has also been echoed by recent research by Maroun and Atkins (2014). Maroun and Atkins' study (2014) indicated that in South Africa there is a need for institutions to improve audit quality ('process' - Figure 3) and the quality information made available to stakeholders ('input' - Figure 3). The authors focused on action-oriented research needed by auditors and emphasised the importance of regulations to enhance the quality of auditing in South Africa in general and the relevance of audit reports.

In addition, Pillay (2014) empirically examined a variety of development fraudulent activities and corruption, reported on an almost daily basis in South Africa. The author indicated that this rampant corruption has increased the country's economic, social, and political costs and that fraud and corruption takes place because of inadequate corporate governance to implement quality auditing. Pillay's approach focuses on an 'input' and 'process' within an IPO framework (Figure 3), namely gathering and analysing data.

In contrast, Ngoc Huy (2013) argued that abundant corporate scandals and bankruptcy happen in Africa because of three contributing factors, namely frail corporate governance, weak internal control systems, and fragile auditing quality. The author proposes strategic policy implications to improve auditing processes ('process - Figure 3) in Africa, particularly in South Africa and Ghana. In line with this study, Nieman and Fouché (2016) emphasised the importance of a regulatory framework in Africa because at present there is no robust framework prescribing requirements for financial reporting. In addition, the existing frameworks and practices do not meet the standard requirements of auditing.

Any regulatory framework is expected to concurrently enhance 'input', 'process', and 'output' of auditing. For example, by enhancing regulatory frameworks, public sector institutions will be able to provide adequate and detailed transaction records, which can be examined satisfactorily by the auditors. At the same time, the public sector institutions in Africa will be able to implement more rigorous processes in auditing the transaction in the public sector such as improve training and development for auditors as well as implementing robust sampling strategies. Lastly, this 'input' and 
or 'process' is expected to enhance the 'output' of the auditing by reducing fraudulent activities and corruption in Africa's public sector. Similarly, Anders's study (2015) revealed that the Malawi government has emphasised the aspects of efficiency and transparency in the public sector through the implementation of technologies ('process' - Figure 3). In fact, the implementation of clean government in Africa in general has been hindered by bureaucratic practises and corruption (Anders, 2015).

An audit sampling strategy can be defined as a strategy to audit 'less than 100 percent' of the items within an account balance or 'less than 100 percent' of the financial transactions within an institution's financial statements in making a conclusion about either the account balance or the financial statement (Hayes, Wallage and Gortemaker, 2014; Johnstone, Gramling and Rittenberg, 2015). Audit sampling techniques are used because it is not practicable for the auditor to examine each single item within the population of an account balance. It is wasteful to investigate each transaction within the population of a financial statement, because of the time and resources involved. However, before selecting a sampling strategy, the auditor needs to define the population to be examined which can be the transactions or the items during the period under review.

The basis for implementing audit sampling is to evaluate the list of items or transactions, which is known as a sampling frame. For example, if it is required to audit 'expense reimbursement schemes' (ERS) in a public-sector organisation, the auditor has to focus on the transactions relating to those staff who travel frequently. ERS can be defined as the falsification of expense information that results in the government overcompensating staff (in the form of inflated expense claims). Hence, any governmental staff member who can incur travel expenses is potentially capable of committing this type of fraud. To audit the possibility of fraud Anderson and Wolfe (2002), suggested that the auditor needs to reconcile all transactions that occurred during the period to the staff's Cash Receipts Journal and Cash Disbursements Journal, along with cross-verification with external parties such as flight or train companies. However, it may not be possible to check all transactions because of the time and resource constraints challenging the auditors. In practice, audit sampling is normally adopted to make a valid conclusion about the whole population. However, earlier research indicates a $20 \%$ rate of alleged failures to detect defalcation and fraudulent corruption in not-for-profit and government institutions (Anderson and Wolfe, 2002).

The auditing theory (Pickett, 2005; Teitlebaum and Robinson, 1975) emphasise two types of audit sampling strategies, namely non-probabilistic (non-random) and probabilistic (random) audit 
sampling. Non-probabilistic sampling includes purposive, convenience and quota audit sampling techniques, while probabilistic audit sampling includes simple random audit sampling, systematic random audit sampling, stratified random audit sampling and cluster random audit sampling.

This paper focuses on 'block selection audit (non-probabilistic) sampling' and 'monetary unit (nonprobabilistic) sampling or MUS' (Questions 12 and 13 in the questionnaire) as well as 'simple random selection' and 'systematic random selection' (Questions 14 and 15 in the questionnaire). Hence, following relevant literature (Pickett, 2005; Teitlebaum and Robinson, 1975), audit sampling strategies used in this study are defined in detail in Table 3 below.

\section{Table 3 - Audit Sampling Strategies}

\begin{tabular}{|c|c|c|}
\hline 1 & $\begin{array}{l}\text { Block selection } \\
\text { audit } \\
\text { non-random } \\
\text { sampling } \\
\text { (BLOCK) }\end{array}$ & $\begin{array}{l}\text { Selecting non-randomly a block of suspect records within the population of accounting records. In } \\
\text { situations where the auditor uses block selection as a non-random sampling technique, many block } \\
\text { samples should be selected to help minimise the non-detection risk, because the block samples may } \\
\text { not be representative of all the records. An example of block selection is where the auditor examines } \\
\text { some of the remittances relating to ERS that are suspected to relate to fraudulent activities, for } \\
\text { example, selecting only records relating to travel expenses to a particular destination. }\end{array}$ \\
\hline 2 & $\begin{array}{l}\text { Monetary unit } \\
\text { non-random } \\
\text { Sampling } \\
\text { (MUS) }\end{array}$ & $\begin{array}{l}\text { Selecting samples based on monetary values to determine the accuracy of the financial accounts. } \\
\text { Each individual pound sterling in an account balance is considered a sampling unit, thus accounts in } \\
\text { the population with a higher balance have a higher chance of being selected. The steps involved in } \\
\text { monetary unit sampling (MUS) are: determining the sample size; purposively selecting the sample; } \\
\text { performing the audit procedures; evaluating the results; and arriving at a conclusion about the } \\
\text { population. For example, by matching an inventory record with a receivable balance, the auditor will } \\
\text { be able to detect misstatements relating to possible fraud and unrecorded government revenues. }\end{array}$ \\
\hline 3 & $\begin{array}{l}\text { Simple } \\
\text { audit random } \\
\text { sampling } \\
\text { (SIMPLE) }\end{array}$ & $\begin{array}{l}\text { Selecting samples to ensure that all items such as accounting records, sales invoices, account } \\
\text { balances and financial information within a population of accounting records have an equal chance } \\
\text { of selection, in which the samples are chosen randomly, for example, by using random number } \\
\text { tables or a random number generator (RNG). }\end{array}$ \\
\hline 4 & $\begin{array}{l}\text { Systematic } \\
\text { audit random } \\
\text { sampling } \\
\text { (SYSTEM) }\end{array}$ & $\begin{array}{l}\text { Selecting }(\mathrm{n}) \text { sample members randomly from the whole population }(\mathrm{N}) \text { according to a random } \\
\text { starting point with a fixed periodic interval }(\mathrm{k}) \text {. Imagine that an auditor wants to find out more about } \\
\text { fraudulent activities in the public sector. Suppose that the government has approximately } 1,000 \\
\text { transactional accounting records from Record } 1 \text { to Record } 1,000 \text {. These } 1,000 \text { records are the } \\
\text { population }(\mathrm{N}) \text {. To select systematic samples of }(\mathrm{n}) \text { records from the population of } 1,000 \text { records, the } \\
\text { auditor could use systematic random selection. For example, the auditor may decide that the desired } \\
\text { sample size is } 5 \% \text {, and } 5 \% \text { x } 1,000=50 \text { samples. Then } \mathrm{k} \text { is estimated to be equal to } \mathrm{N} / \mathrm{n}=1,000 / 50=20 \text {. } \\
\text { The starting point for the sample can be generated randomly by RNG. Let us say that according to } \\
\text { the RNG, the first number of the record that needs to be examined by the auditor is Record } 14 \text {. Then, } \\
\text { the second number that needs to be examined by the auditor is } 14+20=34 \text {, or Record } 34 \text {. The third } \\
\text { is Record } 54(=34+20) \text {. The sample set of the accounting records is therefore } 14,34,54,74,94,114 \text {, } \\
134 \text {, etc. }\end{array}$ \\
\hline
\end{tabular}

Audit sampling technique involve the application of audit procedures to less than $100 \%$ of items within an account balance (Oana and Tatiana, 2013). They authors discussed the origins of audit sampling techniques and provided a brief history of the techniques as well as different definitions from different theoretical perspectives. They concluded that audit sampling is appropriate for testing detailed items and identified the risks and factors affecting the selection of audit sampling procedures, such as nondetection risks, auditing objectives and population characteristics. 
From a non-probabilistic sampling perspective, Danescu and Chis (2012) revealed that audit nonprobabilistic sampling procedures constitute a simple and practical situation, because auditors do not have to study the entire population of transactions within an account balance. Particularly, when the auditor needs to audit a large number of transactions, audit using non-random sampling techniques save considerable time and effort, resulting in lower costs of auditing by inspecting only a fraction of the transactions, or samples only. However, auditors need to use their professional judgement to avoid the risk of non-detection and ensure that the sample represents the population of all transactions to be audited. In the same vein, Burtescu and Grigore (2011) revealed that by selecting samples from the total transactions, the auditor aims to achieve time efficiency, and at the same time reach an efficient conclusion regarding the whole population of transactions. The authors recommended that auditors should use stratified random sampling to optimise the representativeness of the sample and achieve sampling diversity of transactions.

The auditing literature also discusses several aspects of both probabilistic and non-probabilistic audit sampling procedures. For instance, Sibelman (2014) discussed various audit random and non-random sampling techniques, their advantages and disadvantages, and highlighted the role 'practical or nonrandom' sampling techniques in balancing a concern for resource and efficiency. In contrast, Marazi (2016) employed Montecarlo simulation to conclude that by using random (probabilistic) audit sampling, the auditor could minimise financial misstatements. The author indicated that audit random sampling is more efficient than non-random audit sampling, such as monetary unit non-random sampling (MUS). In relation to random audit sampling, Bonnet and Clute (1990) also identified three types of non-sampling errors. They added that in the existence of non-sampling errors, standard audit (non-random) sampling procedures result in a negatively biased estimate of the true number of errors and dollar amounts associated with those errors. Correspondingly, they introduced a double audit sampling technique, such as non-random stratified audit sampling, which can be used to provide an unbiased estimate of the true number of errors and dollar amounts of those errors.

Lastly, Teitlebaum and Robinson's study (1975) indicated that the use of less robust audit sampling procedures results in audit risks such as non-detection, and the associated risks are more significant than predicted. They discussed several factors that affect audit risk, such as population characteristics, sampling design and auditing objectives e.g. problems related to non-random audit sampling in the case of heterogeneous populations i.e. transactions. While this non-random audit sampling can dramatically lower costs, it comes at the expense of introducing bias because the technique itself reduces the likelihood that the sample will represent a cross-section of the population. Hence, non- 
random audit sampling can be an obvious source of sampling error and bias. If Mean Square Error (MSE) can be used as a measure of sampling error (Equation 1), the use of non-random audit sampling leads to higher sample error due to the increased variance (sampling error variability) and bias (systematic sampling error) (Lewis-Beck et al 2004, Rao, 2000) as follow:

$$
\operatorname{MSE}(\mathrm{x})=\mathrm{E}\left[\mathrm{x}-\mathrm{E}(\mathrm{x})^{2}\right]+\mathrm{E}[\mathrm{x}-\mathrm{X}]^{2}=\operatorname{Var}(\mathrm{x})+\operatorname{Bias}^{2}(\mathrm{x})
$$
Equation 1

Where $\mathrm{x}$ is the sample statistic, which is employed to estimate the population parameter $\mathrm{X}, \mathrm{E}$ is expectation operator and MSE is the sum of the variance and the squared bias of the estimate.

In relation to audit non-detection risks, Sahnoun and Zarai's study (2009) used a sample of 200 Tunisian auditors to investigate the relationship between audit risk and auditee business risk and demonstrate that the auditors must devote more attention to auditing an institution's financial statements when the business risk is relatively high. This gives significant messages to the auditors to employ more robust sampling strategies, such as random or probabilistic audit sampling, when business risk is relatively high. A study of audit sampling strategies employed by national and international accounting firms revealed that choosing an audit sampling strategy is the most difficult barrier faced by auditors to identify financial misstatements and fraud, and, these firms use simpler audit sampling strategies because of nonexistence of guidelines on the relative efficiency of audit sampling strategies (Christensen, Elder and Glover, 2015). Because of the paucity of guidelines, the auditors underestimate the non-detection risks and fail to project sample errors when selecting audit sampling techniques and evaluating financial statements (Elder and Allen, 1998; 2003). 


\section{Methodology}

This study employs a quantitative analysis based on a survey carried out to collect data to examine professionals' perception regarding the state of frauds and corruption in Tunisia and other countries such as South Africa and Nigeria and the reasons why people commit frauds, including the types of frauds and corruption. Additionally, the study investigates respondents' opinions (such as professionals, accountants, auditors, senior civil servants and academics) on the use of audit (nonrandom and random) sampling strategies to examine the instances of frauds and corruption.

The use of non-parametric (cross tabulation) statistics was employed, and the SPSS software package was used to carry out quantitative analyses such as descriptive statistics and cross tabulation statistics. The primary data $(n=195)$ was analysed by using a non-parametric test of independence and by examining the closeness of the relationship between the respondents' demographic characteristics and their multiple-choice answers to the survey questions. The reasons for using the non-parametric test were as follows:

- Firstly, a non-parametric test is useful in analysing the categorical or qualitative data collected (Bryman and Bell, 2011), which was based on the multiple choices in the questionnaires.

- Secondly, this study employs a relatively small sample $(n=195)$.

- Thirdly, it further analyses whether respondents' demographic characteristics are dependent or independent of their perception.

- Fourthly, the non-parametric test was also used to evaluate whether the respondents' perceptions (between Tunisia and other countries such as South Africa and Nigeria) differed statistically according to country of origin. This analysis is important since countries like South Africa and Nigeria employ auditing systems similar to that of the UK by following ACCA guidelines (Ngoc Huy, 2014), while Tunisia more closely follows French accounting systems (EI Omari and Khlif, 2014); hence, the non-parametric test was used to evaluate the opinion differential between Tunisia, South Africa and Nigeria.

In general, a non-parametric (Chi-square) test of independence states that if the two variables are independent, the expected frequency (e) values of each cell can be determined by the equation below.

$$
\mathrm{e}=\frac{\left(\mathrm{n}_{\mathrm{i}}\right)\left(\mathrm{n}_{\mathrm{j}}\right)}{\mathrm{N}}
$$


where $i$ is the row $i, j$ is the column $j, n_{i}$ is the total of row $i, n_{j}$ is the total of row $j$, and $N$ is the grand total of all frequencies. Using these expected frequency values and the observed frequency values, a test of independence can be made using Equation 2 to determine whether the variables are independent:

$$
\chi^{2}=\sum \sum\left(\frac{\mathrm{f}_{\mathrm{o}}-\mathrm{f}_{\mathrm{e}}}{\mathrm{f}_{\mathrm{e}}}\right)^{2}
$$

Equation 3

The null hypothesis $(\mathrm{Ho})$ for a Chi-square test of independence is that the two variables are independent. The alternative hypothesis $(\mathrm{Ha})$ is that the variables are not independent. This test is one-tailed with the degrees of freedom of $(r-1)(c-1)$. The decision rule is to reject $\mathrm{Ho}$ if a computing Chi-square produces a critical value from a Chi-square table, otherwise do not reject Ho. Where df stands for degree of freedom, $d f=(r-1)(c-1), r=$ number of rows, $c=$ number of columns, fo=observed frequencies, fe=expected frequencies and $\Sigma$ stands for summation operation.

The survey questionnaires were distributed to more than 300 contacts from Tunisia and Nigeria and South Africa to obtain the perceived values of audit sampling techniques and frauds in the public sector in Africa. From 300 contacts, only 198 responses were received. After removing invalid and incomplete questionnaires, only 195 survey questionnaires fitted the criteria required for statistical analysis using SPSS. The respondents from Tunisia and non-Tunisia countries were purposefully obtained by using a chain-referral sampling technique, which is a non-random sampling technique to aim for heterogeneity of perception among homogenous groups of accountants, auditors, senior civil servants and academics teaching auditing and accounting. In a chain-referral sampling technique, existing respondents recruit future respondents from among their network (Lewis-Beck, Bryman and Liao, 2004; Sedgwick, 2013), in which the respondents are considered to have theoretical knowledge and familiarity in the area of public sector accounting as well as fraudulent and auditing practices in their own country of origin. They include professionals, accountants, bankers, auditors, auditing officers, public sector workers, senior civil servants, senior managers, and academics in auditing and business accounting. The respondents were contacted via Linkedln and provided with a link to the survey questionnaire created on Google Forms.

The survey questionnaires included five and six scales ranging from 1 ('strongly disagree') to 5 ('strongly agree') or from 1 ('it happens all the time') to 6 ('it never happens'). The reliability of the measures is assessed using Cronbach's alpha statistics. The scales were empirically condensed into 
two binary scales to employ binary logistic regression models through a stepwise regression procedure.

A logistic regression model will be employed to complement the descriptive statistics to predict the outcome of a categorical dependent variable based on one or more predictor variables. Algebraically, a Logit (log odds) model of $p$ can be produced using the following equations:

$$
\begin{aligned}
& \text { Odds }=\frac{\pi}{\pi-1} \\
& \log \text { it }(\pi)=\log (\pi)-\log (1-\pi) \\
& \text { Equation } 5
\end{aligned}
$$

The dependent variable in the logistic or logit model is dichotomous. It takes the value 1 with a probability of success $p$, or value 0 with a probability of failure of $1-p$. In the above equations, the base of the logarithm model used is 10 . However, the natural logarithm (In) is the most frequently used in the empirical literature (Agresti, 1996; Kleinbaum, 1997). Accordingly, the logistic regression model of any number $\mathrm{p}$ can be provided algebraically by applying the following equations.

$$
\begin{aligned}
& \log \text { it }(\pi)=\ln \left(\frac{\pi}{\pi-1}\right) \\
& \text { Equation } 6 \\
& \ln \left(\frac{\pi}{\pi-1}\right)=\delta_{0}+\delta_{1} X_{1}+\delta_{2} X_{2}
\end{aligned}
$$

Following Equations 3 and 4, Hosmer and Lemeshow (2000), Menard (1995) and Kleinbaum (1997) reveals that a simple Logit model (with a single predictor variable) can take on Equation 7 for empirical investigation using SPSS.

\section{Findings and Discussion}

\subsection{Descriptive statistics}

The findings indicate that $63.1 \%$ of the respondents are male and $36.9 \%$ are female. Besides, $55.4 \%$ of the respondents are aged between 32 and 38, 18.5\% are aged between 39 and 45, 12.3\% are aged 
between 46 and 52,7.7\% are aged between 25 and 31, and $6.2 \%$ are aged between 53 and 59 . Tunisian respondents constitute $50.8 \%$ of the total respondents, whereas South African and Nigerian respondents represent respectively $29.1 \%$ and $20.1 \%$.

In terms of the respondents' religions, the majority of respondents are Muslim; these respondents were of Tunisian origin. Christianity, as the religion of South Africa and Nigeria, was the second religion among respondents. The remaining respondents were atheists and those who prefer not to state their religion for personal reasons.

The findings also indicate $43.1 \%$ of the respondents have doctoral qualifications, $50.8 \%$ of the respondents have postgraduate qualifications, and $6.2 \%$ of the respondents are qualified to undergraduate degree level. It is, therefore, reasonable to indicate that the majority of respondents are knowledgeable enough to provide quality opinions on the state of auditing and fraud. Moreover, $55.4 \%$ of the respondents have teaching and research roles, while $15.4 \%$ of the respondents have managerial roles as professionals, accountants and auditors, $13.8 \%$ of the respondents have operational or secretarial roles, and $6.2 \%$ of them are in supervisory roles (Table 4).

Table 4 - What is your role within your institution?

\begin{tabular}{|c|c|c|c|}
\hline & Frequency & \% & Cumulative \% \\
\hline Operational or secretarial role & 27 & 13.8 & 13.8 \\
\hline Managerial role & 30 & 15.4 & 29.2 \\
\hline Supervisory role & 12 & 6.2 & 35.4 \\
\hline Teaching or research role & 108 & 55.4 & 90.8 \\
\hline Advisory or consultancy role & 6 & 3.1 & 93.8 \\
\hline Others & 12 & 6.2 & 100.0 \\
\hline Total & 195 & 100.0 & \\
\hline
\end{tabular}

The auditing literature (Murphy and Free, 2016; Roden, Cox and Kim, 2016; Shaio et al., 2017; Lokanan, 2018) identifies three common factors, known as the 'fraud triangle', that lead to fraud and economic crime in the public sector. The first is an incentive or pressure to engage in misconduct. The second is the presence of a bigger opportunity or fewer controls from the management. The third is rationalisation used to justify fraudulent actions, for example, because of their low salaries, managers may be tempted to justify fraud and economic crime. 
The findings indicate that the majority of the respondents agree and strongly agree $(69.2 \%$ and $13.8 \%$, respectively) that an incentive or pressure to engage in misconduct in one's country is always considered as the main cause of the widespread fraud and economic crime in the public sector in Africa (Table 5). Meanwhile, the majority of the respondents also agree and strongly agree $(52.3 \%$ and $26.2 \%$, respectively) that the presence of a bigger opportunity or fewer controls from the management is considered as the first additional cause of the widespread fraud and economic crime in Africa's public sector. Lastly in terms of the fraud triangle, the majority of the respondents $(44.6 \%$ and $33.8 \%$ ) considers that people rationalise to justify their fraudulent actions is considered as the second additional cause of fraud and corruption in Africa. Taking the fraud triangle together, the main cause of widespread fraud and corruption was incentives and pressure to engage in illegal activities compared to other background as indicated in Table 5.

\section{Table 5}

To what extent do you agree that an incentive or pressure to engage in misconduct your country is always considered as the main cause of the widespread fraud and economic crime in the public sector?

\begin{tabular}{|l|c|c|c|}
\hline & Frequency & Percent & Cumulative \% \\
\hline Strongly agree (maximum) & 27 & 13.8 & 13.8 \\
\hline Agree & 135 & 69.2 & 83.1 \\
\hline Neither agree nor disagree & 24 & 12.3 & 95.4 \\
\hline Disagree & 9 & 4.6 & 100.0 \\
\hline Total & 195 & 100.0 & \\
\hline
\end{tabular}

Several types of fraud and corruption are highlighted in the literature (Table 2). In questions 4 to 11 (Appendix 1) the respondents were asked about their awareness of the occurrence of any type of fraud in the public sector during the past twelve months (Table 6). The findings indicate that 'corruption' is the type of fraud that most frequently occurs in Africa and considered to 'happen all the time' (with a mean of 1.692). This is followed by 'asset misappropriation' (with a mean of 1.785) and 'ERS' (with a mean of 1.985). Other fraudulent activities, such as 'espionage' and 'illegal insider trading', are considered to occur less frequently according to the respondents ('it happens rarely') with a mean of 3.108 and 2.738 respectively.

Table 6

To what extent do you agree that has occurred in the public sector during the past twelve months?

\begin{tabular}{|c|c|c|c|c|c|c|c|c|}
\hline & \begin{tabular}{|c|} 
Expense \\
reimbursement \\
schemes (ERS)
\end{tabular} & $\begin{array}{c}\text { Asset } \\
\text { misappropriation }\end{array}$ & Skimming & Corruption & $\begin{array}{c}\text { Shell } \\
\text { companies }\end{array}$ & $\begin{array}{c}\text { Money } \\
\text { laundering }\end{array}$ & Espionage & $\begin{array}{l}\text { Illegal } \\
\text { insider } \\
\text { trading }\end{array}$ \\
\hline
\end{tabular}




\begin{tabular}{|c|c|c|c|c|c|c|c|c|}
\hline Mean & 1.985 & 1.785 & 2.292 & 1.692 & 2.431 & 2.723 & 3.108 & 2.738 \\
\hline Std. Deviation & 0.8195 & 0.8925 & 1.0112 & 0.7890 & 1.1986 & 1.3976 & 1.4483 & 1.3261 \\
\hline
\end{tabular}

When asked to suggest the most efficient audit sampling strategy for investigating fraudulent activities or economic crime within the public sector in Africa, the majority of the respondents chose 'block selection audit (non-random) sampling' (with a mean of 2.046), followed by 'monetary unit sampling (non-random)' (with a mean of 2.200). Although audit random sampling strategies, such as 'simple audit random sampling' and 'systematic audit random sampling', are considered as the most efficient sampling in auditing (Teitlebaum and Robinson, 1975), in this study, audit random sampling is found to be less important, with a mean of 2.754 (Table 6). Possible explanations for the phenomena are that the science of audit sampling was not widespread in the auditing community in Africa. In comparison, earlier studies in the application of audit sampling techniques (such as Elder and Allen, 1998, 2003; Marazzi, 2016; Marazzi and Tille, 2017) reveal that audit random sampling strategies were not widely used among practitioners.

The coefficient of skewness (Table 7) is a measure of the asymmetry of the probability distribution of the respondents' opinion, which can be positive or negative. The coefficients of skewness of block selection audit sampling, monetary unit sampling, simple audit random sampling and systematic audit random sampling are found to be $0.571,0.836,-0.188$ and -0.040 respectively. The findings indicate that the distribution of opinion preferring block selection audit sampling and monetary unit sampling is negatively skewed, while the opinion preferring simple audit random sampling and systematic audit random sampling is positively skewed. It is reasonable to expect that these types of skewness occur because most of the respondents prefer to use audit non-random sampling (block selection audit sampling and monetary unit sampling) rather than audit random sampling (simple audit random sampling and systematic audit random sampling). On average, most of the respondents who preferred to use non-probabilistic sampling share similar opinions, tending to agree with one other as indicated by relatively lower standard deviations of 0.8372 and 0.8874 respectively (Table 7).

Table 7

To what extent do you agree that is the most efficient methodology to detect fraudulent activities or economic crime within the public sector?

\begin{tabular}{|c|c|c|c|c|}
\hline & $\begin{array}{c}\text { Block selection audit } \\
\text { sampling }\end{array}$ & $\begin{array}{c}\text { Monetary unit } \\
\text { sampling (MUS) }\end{array}$ & $\begin{array}{c}\text { Simple audit random } \\
\text { sampling }\end{array}$ & $\begin{array}{c}\text { Systematic audit } \\
\text { random sampling }\end{array}$ \\
\hline Mean & 2.046 & 2.200 & 2.754 & 2.754 \\
\hline Std. Deviation & 0.8372 & 0.8874 & 1.0312 & 0.9525 \\
\hline Skewness & 0.571 & 0.836 & -0.188 & -0.040 \\
\hline
\end{tabular}


The findings showed that audit non-random sampling strategies are more preferred by the respondents than those of audit random sampling strategies. This is in line with the earlier studies of Elder and Allen (1998; 2003) who claimed that auditors do not consider sampling risks when identifying financial misstatements and fraud detection risks in general. Although earlier studies, such as Marazzi (2016) and Marazzi and Tille (2017), indicate that audit random sampling techniques are more efficient than audit non-random techniques such as block selection sampling and monetary unit sampling (MUS), most of the respondents consider the use of audit non-random sampling techniques as preferable.

\section{Reliability test}

To assess the scales the scale reliability Cronbach's Alpha coefficients. A relatively high value of Cronbach's alpha is often used to prove that the items measure an underlying construct (Bonnent and Wright, 2014; Lewis-Beck, Bryman and Liao, 2004; Sijtsma, 2009; Vaske, Beaman and Sponarski, 2017). The closer the Cronbach Alpha is to 1, the greater the internal consistency of the scale is (Lewis-Beck, Bryman and Liao, 2004; Sijtsma, 2009; Vaske, Beaman and Sponarski, 2017). Overall, the findings reveal that the reliability is robust $(C A=0.74)$, being higher than 0.7 . That said, the questions are consistent and reliable enough to measure common factors (fraud, corruption and types of fraud, as well as the audit sampling strategy preference in detecting fraud).

Following the earlier discussion on descriptive statistics, this section offers inferential statistics of the findings. Inferential statistics enable the reader to analyse the data further by relating the respondents' demographics with their perceived values, in addition to proposing 'soft' generalisations about the populations from which the respondents come from; namely, Tunisia and non-Tunisia countries (South Africa and Nigeria). However, as discussed earlier, these findings offer valuable direction for future studies on audit sampling strategies that aim to tackle the rampant fraud and corruption in Africa. The discussions of inferential statistics include the estimation of parameters (of the non-parametric tests such as Chi Square test) and testing of possible hypotheses.

Following relevant methodical literature (Auerbach and Silverstein, 2003; Platt et al., 2006; Polit and Beck, 2007; Volz and Heckathorn, 2008), the respondents were selected by using a chain-referral sampling technique. The technique can be defined as special non-probability sampling used effectively when the sample characteristics are rare and difficult to contact, such as auditors, professional accountants, senior civil servants, and academics, who are knowledgeable in the areas of auditing in an Africa context. In chain-referral sampling, additional respondents were selected by initial respondents based on their network of contacts. This type of sampling, which is based on referrals 
from the initial respondents, is very useful for this research because it is difficult nowadays to find people and potential respondents who are willing to fully answer survey questionnaires. Hence, such individuals and potential respondents within their own groups are difficult to identify because the target population is thinly dispersed among larger populations. Many companies and market research agencies are constantly researching people, at all times. Consequently, many people refuse to participate to surveys anymore, feeling they have been overly researched and believing that it wastes their valuable time (Agarwal et all., 2016; Phillips, Reddy and Durning, 2016).

\section{Relationship between demographics and respondents' opinions}

In order to investigate the relationship between the respondents' demographics and their opinions, Spearman's rank correlation coefficient was computed. In line with previous literature, this study uses Spearman's coefficient instead of Pearson's, as the primary data was ordinal rather than ratio (Gibbons and Chakraborti, 2010; Lewis-Beck, Bryman and Liao, 2004). The Chi Square test was applied to understand whether there was a difference in opinion about the types of fraud in Tunisia and nonTunisian countries, the common factors causing fraud and corruption, and the preferences of using audit random and non-random sampling between Tunisia and non-Tunisia countries. Initially, it was expected that the patterns (expected perceived values) would be different between the three selected countries because, South Africa and Nigeria predominantly follow the Association of Chartered Certified Accountants, or ACCA, as the global body for professional accountants, headquartered in London. Also, Tunisian respondents have different faith affiliation compared to the respondents from South Africa and Nigeria. This religious difference was expected to show different opinion regarding types of fraud, the common causes of frauds and preferred audit sampling strategies to detect the fraud. However, the findings indicate that there is no significant difference in respondents' opinion regarding the perceived values of audit sampling and people in different parts of Africa i.e. Tunisia, South Africa and Nigeria share a common opinion regarding the issues.

Table 8 presents Spearman's rho between the respondents' preferred audit sampling strategies and their demographic characteristics. Interestingly, the findings indicate Spearman's rho values respectively -0.390 and -0.379 . The coefficient correlation is statistically significant at the 0.01 level. Hence, it can be concluded that more educated respondents prefer to apply audit random sampling strategies to investigate fraud and corruption. Several cross-tabulations were also tried among the respondents' demographic status and their opinion, but the results were not statistically significant and was not reported. 
Table 8 - Spearman rho (Refer to the note below)

\begin{tabular}{|l|c|c|}
\hline & $\begin{array}{c}\text { To what extent do you agree that simple } \\
\text { random selection auditing is the most efficient } \\
\text { methodology to detect fraudulent activities or } \\
\text { economic crime within the public sector? }\end{array}$ & $\begin{array}{c}\text { To what extent do you agree that systematic } \\
\text { random selection auditing is the most efficient } \\
\text { methodology to detect fraudulent activities or } \\
\text { economic crime within the public sector? }\end{array}$ \\
\hline $\begin{array}{l}\text { Correlation } \\
\text { Coefficient }\end{array}$ & $-0.390^{* *}$ & $-0.379 * *$ \\
\hline Sig. (2-tailed) & 0.001 & 0.002 \\
\hline
\end{tabular}

The cross-tabulation test of Chi Square (Table 9) was performed on Questions 22 (the respondents' country of origin) and 15 (the respondents' preference of audit sampling strategies to investigate fraud and corruption). The findings reveal a not statistically significant Chi square with a value of 2.896 . This implies that the same preferences of the respondents from the three countries; the respondents from Tunisia, South Africa and Nigeria have similar preferential opinions regarding audit sampling strategies.

Similarly, the cross-tabulation test was implemented to investigate the relationship between the respondents' country of origin and the types of fraud and corruption activity that existed in their country. Overall, the findings, except the findings on 'skimming' fraud, indicate that the respondents from Tunisia, South Africa and Nigeria relatively share the same opinion regarding the types of fraud that occur in their countries. Besides, the findings related to skimming fraud indicate that the respondents from Tunisia believe that this activity occurs less frequently than in South Africa and Nigeria, while the respondents from South Africa and Nigeria indicate that skimming fraud takes place more frequently. A possible explanation for this divergence is, although South Africa's and Nigeria's accounting systems follow International Standards on Auditing (ISA) (Charlton, 2009; Wisdom and Oyebisi, 2017), there are more opportunity to commit this fraud, in which cash is removed from the government office before it enters the accounting system.

Table 9 - Chi-Square Tests (Refer to the note below)

\begin{tabular}{|c|c|c|c|}
\hline & Value & Df & $\begin{array}{c}\text { Asymptotic Significance } \\
\text { (2-sided) }\end{array}$ \\
\hline Pearson Chi-Square & 2.896 & 3 & 0.408 \\
\hline Likelihood Ratio & 3.031 & 3 & 0.387 \\
\hline Linear-by-Linear Association & 1.614 & 1 & 0.204 \\
\hline N of Valid Cases & 195 & & \\
\hline
\end{tabular}

Note: The tests are not significant (Column 4) implying relatively similar preferential opinions regarding audit sampling strategies between the countries. 


\subsection{Regression Analysis}

A simple logistic regression model was employed in order to identify the relationship between the respondents' country of origin and the respondents' perception on the efficiency of audit sampling techniques. The results from the simple logistic model with the respondents' country of origin as the independent variable (1=non-Tunisia; $2=$ Tunisia) reveal that the independent variable is a significant predictor with $p<0.05(=0.047)$, which is indicated by the "Sig." column in Table 10.

Table 10 - A logistic regression model (SPSS output) (Refer to the note below) Dependent variable $(\mathrm{Y})$ : The perceived efficiency of block selection sampling ( 0 =inefficient; $1=$ efficient)

\begin{tabular}{|c|r|r|r|r|r|r|}
\hline & B & S.E. & Wald & df & Sig. & $\operatorname{Exp}(B)$ \\
\hline Constant & 0.974 & 0.399 & 5.959 & 1 & 0.015 & 2.650 \\
\hline Block $\left(X_{1}\right)$ & -0.305 & 0.172 & 3.135 & 1 & 0.047 & 0.737 \\
\hline
\end{tabular}

Note: The coefficients are significant at the $1 \%$ and $5 \%$ levels respectively (Column 6 - Sig.)

The simple logistic regression model can be stated in either additive or multiplicative form. Based on Table 10, the additive and multiplicative forms of the simple logistic regression model can be written consecutively as follows:

$$
\begin{aligned}
& \ln \frac{\pi}{1-\pi}=\beta_{0}+\beta_{1} X_{1} \\
& \ln \frac{\pi}{1-\pi}=0.974+0.305 X_{1} \\
& \frac{\pi}{1-\pi}
\end{aligned}=\mathrm{e}^{0.974-0.305 \mathrm{X}_{1}}
$$

Ln $(\pi / 1-\pi)$ is known in the literature (Hoetker, 2007; Pampel, 2000; Agresti, 1996; Zaloumis, 2015) as the log-odds and $(\pi / 1-\pi)$ as the odds, while e is exponential functions, as they are the odds multipliers. Accordingly, by using the simple logistic regression model, with one explanatory variable of the usage of block selection audit non-random sampling, the odds that a subject of given classification can be predicted accordingly, whether or not a respondent from a particular country will employ block selection audit sampling because of the perceived efficiency of block selection audit sampling. 
Block selection audit non-random sampling involves selecting non-randomly a block of suspected accounting records or samples within the population of all accounting records. In situations when the auditor uses only block selection as a non-random sampling technique, many block samples should be selected to help minimise the non-detection risk because the block samples may not represent the whole accounting records.

Correspondingly, the respondents, professional and auditors from South Africa and Nigeria $\left(X_{1}=1\right)$ is 1.952 times more likely to utilise block selection sampling because they consider block selection sampling is an efficient auditing tool. Whilst, the professionals and accountants from Tunisia $\left(X_{1}=2\right)$ is only 1.439 times more likely to employ block audit sampling. Hence, compared to the professionals and accountants from Tunisia, the professionals and auditors from South Africa and Nigeria examine carefully more of the accounting remittances, which are suspected of fraudulent activities having happened. Possible explanations for the phenomena are that South Africa's and Nigeria's legal, accounting and regulatory systems are more consistent with international standards (Charlton, 2009; Wisdom and Oyebisi, 2017).

By converting the odds to probabilities of Equations 8 to 10, it yields Equation 11 as follows:

$$
\pi=\frac{\mathrm{e}^{0.974-0.305 \mathrm{X}_{1}}}{1+\mathrm{e}^{0.974-0.305 \mathrm{X}_{1}}}
$$
Equation 11

The simple logistic regression model predicts that $66 \%$ of the professionals, accountants and auditors from South Africa and Nigeria $\left(X_{1}=1\right)$ will employ block selection (non-random) sampling, whilst the model forecasts that only $59 \%$ of the respondents, accountants and auditors from Tunisia $\left(X_{1}=2\right)$ will utilise block selection (non-random) sampling to audit fraudulent records.

A stepwise regression procedure was implemented by adding other explanatory and interactive variables (interaction effects) as well as incorporating other dependent variables such as the perceived efficiency of monetary unit sampling (Question 13), simple random selection auditing (Question 14) and systematic random selection auditing (Question 15). However, the results are not significant, the finding of the simple logistic regression model is in line with the statistics provided in Table 7 that the majority of the respondents chose 'block selection audit sampling' with a mean of 2.046. which is in line with previous findings showing that auditors prefer to employ non-random audit sampling in practice (Elder and Allen, 1998; 2003) 
Lastly, multinomial logistic regression models using more than two categories are also implemented following Garson (2012) but the results were not acceptable. This result could be explained by the small sample size (195) which could hinder sophisticated multinomial logistic regression models and the degree of freedom was lost.

\section{Conclusion and Policy Implications}

This study investigates how people in Tunisia, South Africa and Nigeria perceive the types of fraud in Africa, the causes of such fraud, and the audit sampling strategies used to investigate the frauds. Although there are some minor statistical differences between the countries in terms of the respondents' perceived values on skimming fraud and the use of audit random sampling to tackle rampant corruption in Africa, the overall findings indicate that opinions do not significantly differ between the respondents from Tunisia, South Africa and Nigeria in terms of the types of fraud, the reasons for committing fraud and the auditing sampling strategies used to investigate the frauds.

This study could assist governments, policy makers and academia to improve the country's audit sampling strategy to combat fraud and corruption using audit random sampling rather than audit nonrandom sampling. Moreover, audit firms and policy makers need to be vigilant to apply audit sampling techniques in order to improve the countries' performances and minimise the fraud level. Nevertheless, it is suggested that future studies on audit sampling strategies aiming to minimise fraudulent activities and corruption within the public sector in Africa could be enhanced by undertaking the following aspects:

- Since Africa has suffered from fraudulent practices and corruption in recent decades, future studies may utilise larger sample sizes among several African countries so that a comprehensive generalisation can be made. In addition, by employing larger datasets, a more robust analysis can be performed.

- Future studies can use actual values instead of perceived values of the respondents' opinions. For example, real audit data could be obtained from any public sector office in Africa, meaning various hypothetical audit sampling strategies can be performed in relation to the potential errors generated within the accounting population. This type of study could be analysed by using Monte Carlo simulations. Then, a relationship could be established between audit sampling strategies and their efficiency or effective detection rates so the efficiency of audit sampling strategies can be estimated according to an Africa context. 
- To complement the quantitative analysis conducted, a qualitative analysis using interviews and observations could be conducted to evaluate the effectiveness of various audit sampling strategies in relation to the fraudulent and corruptive activities in the public sector in Africa.

- The findings indicate that audit non-random sampling techniques are more preferred by the respondents than those of audit random sampling technique. However, this non-random technique increases fraud and corruption. Accordingly, the government should develop strategic policies and facilitate training and workshops on audit random sampling to educate accountants, auditors and financial advisors since audit random sampling techniques are more efficient than audit non-random techniques to detect fraudulent activities.

- Since big data is increasingly playing a significant role in the auditing practice, further investigations into the application of audit sampling techniques appropriate to handle big data are recommended. For example, the methodology of automation and artificial intelligence are required by auditors to inspect a massive amount of big data on the Internet. The findings of this study could be applied to big data and more efficient audit random sampling strategies could be employed to lower the non-detection risks and detect fraud and corruption.

- This study carries limitations. This research analyses a limited number of countries: Tunisia and other countries such as South Africa and Nigeria. Correspondingly, the findings may not represent the perceived values and opinions of the whole populations of African countries; however, the findings are valuable as an analytical exploration to instigate the potential application of audit sampling strategies for detecting fraudulent activities and corruption in Africa by researching several African countries to achieve stronger generalisation. 


\section{References}

Agarwal, A., Raad, D., Kairouz, V., Fudyma, J., Curtis, A. B., Schünemann, H. J. and Akl, E. A. (2016). "The effect of a monetary incentive for administrative assistants on the survey response rate: a randomized controlled trial", BMC Medical Research Methodology, pp. 161-165.

Anders, G. (2015). "The normativity of numbers in practice: Technologies of counting, accounting and auditing in Malawi's civil service reform", Social Anthropology / Anthropologie Sociale, Serial Online, Vol. 23, No. 1, Issue February.

Anderson, S. and Wolfe, J. (2002). "A Perspective on Audit Malpractice Claims: CPAs can take steps to avoid preventable litigation", Journal of Accountancy, Issue September, Accessed electronically from http://www.journalofaccountancy.com/issues/2002/sep/

Appelbaum, D., Kogan, A. and Vasarhelyi, M. (2017). 'Big Data and Analytics in the Modern Audit Engagement: Research Needs', Auditing: A Journal of Practice \& Theory, Vol. 36, pp. 1-51.

Armah-Attoh, D., Gyimah-Boadi, E. and Chikwanha, A. B. (2007). "Corruption and Institutional Trust in Africa: Implications for Democratic Development", Afrobarometer Working Papers, Vol. 81, Issue December, Ghana, Publisher: the Centre for Democratic Development (CDD).

Beldona, S. and Francis, V. E. (2007). "Regression analysis for equipment auditing", Managerial Auditing Journal, Vol. 22, No. 8, pp. 809-822.

Boly, A., Konte, M. and Shimeless, A. (2020). Corruption and Tax Morale in Africa, Working Paper, Vol. 333, Issue: 25 May 2020, pp. 1-28, African Development Bank Group, Accessed electronically 14 September 2021 from https://www.afdb.org/en/documents/working-paper333-corruption-and-tax-morale-africa

Bonnet, D. G. and Clute, R. C. (1990). "Audit sampling with non-sampling errors of the first type", Contemporary Accounting Research, Vol. 6, No. 2, pp. 432-445.

Bonnent, D. G and Wright, T. A. (2014). “Cronbach's alpha reliability: Interval estimation, hypothesis testing, and sample size planning", Journal of Organizational Behavior, Vol. 36, Issue: October, pp. 3-15.

Burtescu, C. and Grigore, G. (2011). "Sampling in Audit and Professional Reasoning", Agricultural Management, Lucrari Stiintifice Serial, Management Agricol, Vol. 13, No. 3, pp. 165-172.

Charlton, G. (2009). "An investigation into the impact of continuous auditing on the external auditors of the four largest banks in South Africa", South Africa Journal of Accounting Research, Vol. 23, No. 1, Issue: January, pp. 45-65.

Chen, Y. and Leitch, R. A. (1999). "Analysis of the relative power characteristics of analytical procedures", Auditing: A Journal of Practice and Theory, Vol. 18, No. 2, pp. 35-69.

Christensen, B., Elder, R. and Glover, S. (2015). "Behind the numbers: Insights into large audit firm sampling policies", Accounting Horizons, Serial Online, Vol. 29, No. 1, Issue March, pp.61-81. 
Danescu, T. and Chis, A. (2012). "Opportunity and Necessity in Audit Sampling Non-statistical Sampling Method", Procedia Economics and Finance, Vol. 3, pp. 1128-1133, International Conference Emerging Markets Queries in Finance and Business, Petru Maior University of Tirgu-Mures, ROMANIA, October 24th - 27th, 2012).

Durney, M., Elder, R. J. and Glover, S. M. (2014). "Field Data on Accounting Error Rates and Audit Sampling", Auditing: A Journal of Practice and Theory, Vol. 33, No. 2, pp. 79-110, Publisher: American Accounting Association.

El Omari, S. and Khlif, W. (2014). "Professionnalisation des experts-comptables : analyse comparée du Maroc et de la Tunisie", Comptabilité - Contrôle - Audit 1/2014 (Tome 20) , pp. 67-91.

Elder, R. J., and R. D. Allen. (1998). "An empirical investigation of the auditor's decision to project errors", Auditing: A Journal of Practice and Theory, Vol. 17, No. 2, pp. 71-87, Publisher: American Accounting Association.

Elder, R. J., and R. D. Allen. (2003). "A longitudinal field investigation of auditor risk assessments and sample size decisions", the Accounting Review, Vol. 78, No. 4, pp. 983-1002.

Elder, R. J., Akresh, A. D., Glover, S. M., Higgs, J. L. and Liljegren, J. (2013). “Audit Sampling Research: A Synthesis and Implications for Future Research", Auditing: A Journal of Practice and Theory, Vol. 32, No. Supplement 1, pp. 99-129, Publisher: American Accounting Association.

Felix Jr, W. L. and Grimlund, R. A. (1977). "A Sampling Model for Audit Tests of Composite Accounts", Journal of Accounting Research, Vol. 15, No. 1, pp. 23-41.

Gibbons, J. D. and Chakraborti, S. (2010). "Nonparametric Statistical Inference", Statistics: Textbooks and Monographs, 5th Edition, Boca Raton, USA, Publisher: Chapman and Hall/CRC.

Gustavson, M. (2014). Auditing good government in Africa: Public sector reform, professional norms and the development discourse, Basingstoke, UK, Publisher: Palgrave Macmillan.

Hayes, R., Wallage, P. and Gortemaker, H. (2014). Principles of Auditing: An Introduction to International Standards on Auditing, 3rd Edition, London, UK, Publisher: Pearson Higher Education, ISBN: 13-9780273768173.

Heath, W. (2000). "South Africa: Public Sector Corruption", Journal of financial crime, Vol. 7, No. 4, pp. 373-76.

Johnson, G. G. and Mohsen, A. A. (2013). "Monetary Unit Sampling: Combining Accounts for Sampling to Increase Audit Efficiency and Effectiveness - When and How", International Journal of Business, Accounting and Finance, Vol. 7, No. 1, pp. 152-165.

Johnstone , K. M., Gramling, A. A. and Rittenberg, L. E. (2015). Auditing: A Risk Based-Approach to Conducting a Quality Audit, Mason, USA, Publisher Cengage Learning Inc.

Lewis-Beck, M.S, Bryman, A and Liao, T.F (Editors). (2004). Social Science Research Methods, London, UK, Publisher: Sage Publications, ISBN: 0-7619-2363-2.

Lokanan, M. (2018). "Informing the fraud triangle: Insights from differential association theory", The Journal of Theoretical Accounting Research, Vol. 14, No. 1, pp. 55-98. 
Marazzi, A. (2016). "Using past experience to optimize audit sampling design", Review of Quantitative Finance and Accounting, Serial Online, Vol. August, pp. 1-28.

Marazzi, A. and Tillé, Y. (2017). "Using past experience to optimize audit sampling design", Review of Quantitative Finance and Accounting, Vol. 49, No. 2, pp. 435-62.

Maroun, W. and Atkins, J. (2014). "Section 45 of the Auditing Profession Act: Blowing the whistle for audit quality?", the British Accounting Review, Serial Online, Vol. 46, Issue September, pp. 248263.

Murphy, P. R. and Free, C. (2016). "Broadening the Fraud Triangle: Instrumental Climate and Fraud", Behavioral Research in Accounting, Vol. 28, No. 1, pp. 41-56.

Ngoc Huy, D. (2013). "The Appraisal of Comparative African Corporate Governance Standards after Global Crisis", Economic Insights - Trends and Challenges, Serial Online, Vol. 65, No. 2, Issue June, pp. 20-35.

Ngoepe, M. and Ngulube, P. (2016). "A framework to embed records management into the auditing process in the public sector in South Africa", Information Development, Vol. 32, No. 4, pp. 890903.

Nieman, G. and Fouché, K. (2016). “Developing a regulatory framework for the financial, management performance and social reporting systems for co-operatives in developing countries: A case study of South Africa", Acta Commercii, Serial Online, Vol. 16, No. 1, Issue January, pp. 1-7.

Nyamori, R. O., Abdul-Rahaman, A. and Grant, S. (2017). "Accounting, auditing and accountability research in Africa", Accounting, Auditing and Accountability Journal, Vol. 30, No. 6, pp. 12061229.

Oana, C. and Tatiana, D. (2013). "Convergence of International Audit Standards and American Audit Standards regarding Sampling", Annals of the University of Oradea, Economic Science Series, Serial Online, Vol. 22, No. 1, Issue July, pp. 1310-1315.

Peek, L., Neter, J. and Warren, C. (1991). "AICPA Non-Statistical Audit Sampling Guidelines: A Simulation", Auditing: A Journal of Practice and Theory, Vol. 10, No. 2, pp. 33-48.

Phillips, A. W., Reddy, S. and Durning, S. J. (2016). "Improving response rates and evaluating nonresponse bias in surveys: AMEE Guide No. 102", Medical Teacher, Vol. 38, No. 3, Issue March, pp. 217-228.

Pickett, S. (2005). The essential handbook of internal auditing, Chichester, UK, Publisher: John Wiley and Son.

Pillay, S. (2014). Development corruption in South Africa: Governance matters, Basingstoke, UK, Publisher: Palgrave Macmillan.

Platt, L., Wall, M. and Rhodes, T., Judd, A., Hickman, M., Johnston, L., Renton, A., Bobrova, N. and Sarang, A. (2006). "Methods to Recruit Hard-to-Reach Groups: Comparing Two Chain Referral 
Sampling Methods of Recruiting Injecting Drug Users Across Nine Studies in Russia and Estonia", Journal of Urban Health, Vol. 83, No. 7, Issue: November, pp. i39-i51.

PWC. (2016). 2016 PWC Tunisia Transparency Report, Vol. August, PWC stands for Price Waterhouse Coopers International Ltd., Tunis, Tunisia, Publisher: PWC.

Rao, P.S.R.S. 2000. Sampling Methodologies with Applications, Florida, USA, Publisher: Chapman and Hal / CRC Press LLC, ISBN: 1-58488-214-X.

Roden, D. M., Cox, S. R. and Kim, J. Y. (2016). "The Fraud Triangle as a Predictor of Corporate Fraud", Academy of Accounting and Financial Studies Journal, Vol. 20, Issue 1, pp. 80-92.

Sahnoun, M. and Zarai, M. (2009). "Auditor-Auditee Negotiation Outcome: Effects of Auditee Business Risk, Audit Risk, and Auditor Business Risk in Tunisian Context", Corporate Governance: An International Review, Serial Online, Vol. 17, No. 5, Issue September, pp. 559572.

Sedgwick, P. (2013). “Snowball sampling; Statistical Question”, British Medical Journal, 347, pp. 1-2.

Shaio, Y. H., Chi-Chen, L., An-An, C. and Yen, D. C. (2017). "Fraud detection using fraud triangle risk factors", Information Systems Frontiers, Vol. 19, No. 6, pp. 1343-56.

Sibelman, H. (2014). "Myths and Inconvenient Truths about Audit Sampling, CPA (Certified Public Accountant) Journal, Vol. 84, No. 4, pp. 6-10.

Sijtsma, K. (2009). "On the use, the misuse, and the very limited usefulness of cronbach's alpha", Psychometrika, Vol. 74, No. 1, pp. 107-120.

Slama, F. B. and Klibi, M. F. (2017). "Accounting development in a changing environment: the case of Tunisia", International Journal of Law and Management, Vol. 59, No. 5, pp. 756-75.

Soobaroyen, T., Tsamenyi, M. and Sapra, H. (2017). "Accounting and governance in Africa contributions and opportunities for further research", Journal of Accounting in Emerging Economies, Vol. 7, No.4, pp. 422-427.

Teitlebaum, A. D. and Robinson, C. F. (1975). "The Real Risks in Audit Sampling", Journal of Accounting Research, Vol. 13, No. 3, pp. 70-91.

Transparency International (2020), 'CPI 2020: Sub Saharan Africa", Accessed electronically from https://www.transparency.org/en/news/cpi-2020-sub-saharan-africa

Tranparency.org (2019), "Are African countries preventing corruption and prosecuting related crime", Accessed electronically from https://www.transparency.org/en/news/are-africancountries-preventing-corruption

Vaske, J. J., Beaman, J. and Sponarski, C. C. (2017). "Rethinking Internal Consistency in Cronbach's Alpha”, Leisure sciences: An interdisciplinary journal, Vol. 39, No. 2, pp. 163-73.

Volz, E. and Heckathorn, D. D. (2008). "Probability Based Estimation Theory for Respondent Driven Sampling", Journal of Official Statistics, Vol. 24, No. 1, Issue: March, pp. 79-97. 
Vasarhelyi, M.A., Kogan, A. and Tuttle, B. M. (2015). 'Big data in accounting: An overview', Accounting Horizons, Vol. 29, No. 2, pp. 381-396.

Warf, B. (2017). 'Geographies of African corruption', PSU Research Review, Vol. 1, No. 1, pp. 20-38.

Wisdom, O. and Oyebisi, O. (2017). 'Impact of public sector auditing in promoting accountability and transparency in Nigeria', Journal of Internet Banking and Commerce, Vol. 22, No. 3, pp. 1-8.

World Bank. (2006). Republic of Tunisia: Accounting and Auditing, Washington, USA, Publisher: World Bank, Accessed electronically 18 December 2018, from https://openknowledge.worldbank.org/handle/10986

Yeboah-Assiamah, E. (2016). A socio-cultural approach to public sector corruption in Africa: key pointers for reflection", Journal of Public Affairs, Vol. 16, No. 3, pp. 279-93.

Zaloumis, S. G. (2015). "Non-proportional odds multivariate logistic regression of ordinal family data", Biometrical Journal, Vol. 57, No. 2, Issue: January, pp. 286-303. 